\title{
Design and Analysis of Slot Loaded Reconfigurable Microstrip Patch Antenna for Different Frequency Bands
}

\author{
Shuchita Saxena, Kshitij Shinghal, Amit Saxena, Deepti Shinghal \\ Department of E\&C Engineering, MIT, Moradabad, U.P., India \\ shuchita1210@gmail.com
}

\begin{abstract}
Antenna whose design has been suggested is composed of a simple dual band antenna having a size of 60mm $x$ $40 \mathrm{~mm} \times 1.6 \mathrm{~mm}$. The reconfiguration has been achieved by PIN diode. The antenna is fabricated on FR4 substrate. The bandwidth of the antenna is increased for both the bands and also the impedance matching is improved when the diode is in the ON state. The proposed antenna operates at $3.8 \mathrm{GHz}$ and $4.3 \mathrm{GHz}$ bands when the diode is OFF and the two bands exhibit bandwidth of $70 \mathrm{MHz}$ and $100 \mathrm{MHz}$ for the lower and upper band. On activating the diode the resonant frequency shifts to left hand side and the loaded antenna operates at $3.7 \mathrm{GHz}$ and 4.12 $\mathrm{GHz}$ bands and the antenna now exhibit bandwidth of $90 \mathrm{MHz}$ and $210 \mathrm{MHz}$ for the two bands.
\end{abstract}

KEYWORDS - Rectangular Patch antenna, reconfigurable antenna, multi band antenna, HFSS.

\section{INTRODUCTION}

Reconfigurable antennas have many benefits as compared to the conventional antennas and have been used in many applications [1-4]. A large number of functions can be achieved from a single antenna. The antenna element itself can be made reconfigurable by modifying the antenna geometry. PIN diodes are commonly used to redirect the flow of the currents in the antenna, therefore modifying the operation. Also the antenna size and the cost of the antenna is reduced for a reconfigurable antenna as only one antenna is made to perform separate task. The dynamic property of the antenna can be achieved with the help of elements, for example RF switches such as PIN diode, MEMS and GaAS FETs.. PIN diode is much simpler to be integrated with the antenna as compared to RF MEMS [5-7]. These switches are made to operate in the $\mathrm{ON}$ and OFF mode to make the antenna reconfigurable. There are different methodologies through which we can achieve antenna reconfigurability [8-12]. Reconfigurable antennas can be classified into three main categories based on their ability to change any one of the following parameters: (a) frequency [13] (b) radiation pattern [14] (c) polarization [15, 16]. The performance characteristic of the antenna can be changed by altering the current flow on an antenna using mechanically movable pats, diodes, tunable materials or active materials.

This paper uses the frequency reconfiguration technique to control the antenna bandwidth. With the increasing demand of bandwidth, many researchers are doing efforts to make the antennas reconfigurable so that the same antenna can work on more than one frequency band. But the biggest challenge that the researcher faces is how to connect the radiating elements together to make them operate on different frequency bands. To connect these radiating elements different switching circuitry are used. Switching elements also require proper biasing networks for the activation and deactivation of the switch which may increases the complexity of antenna and can also vary the performance of antenna.

In this paper PIN diode is used either in the ON or OFF state to change the state of the antenna from a simple patch to frequency reconfigurable antenna. The design of the antenna as well as the simulated results are fully discussed. By controlling the state of the switch, the patch antenna can operate in different frequency bands. 


\section{ANTENNA DESIGN}

The geometries of the designed slot loaded reconfigurable microstrip patch antenna is shown in figure 1 .

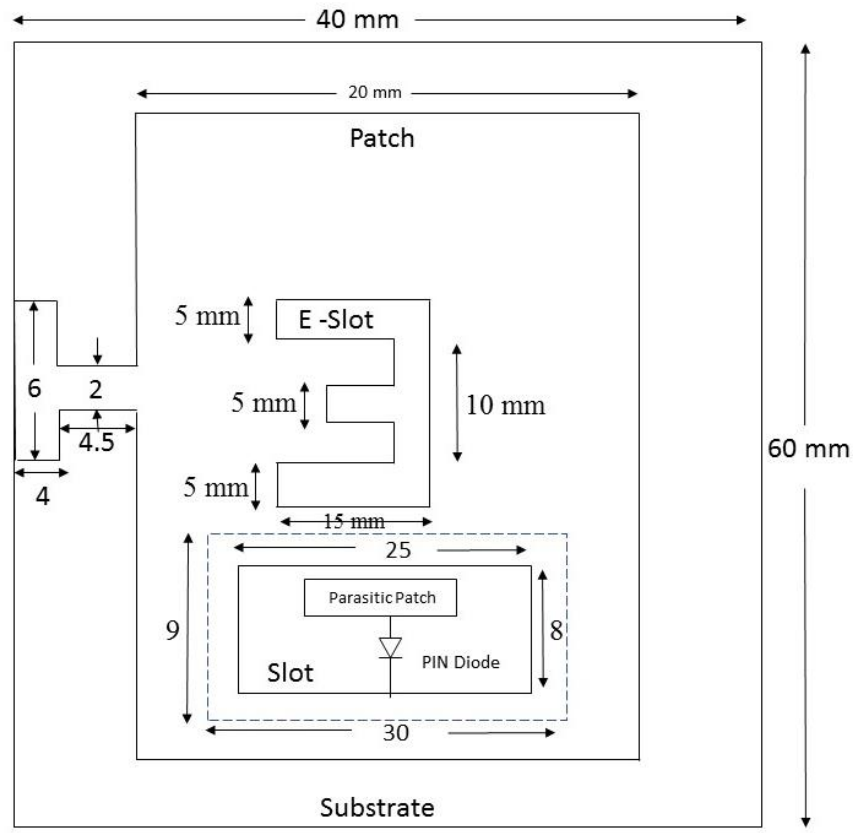

Figure-1: geometry of the designed slot loaded reconfigurable microstrip patch antenna

The proposed antenna is printed on a FR4 substrate with relative permittivity 4.4 and height $1.6 \mathrm{~mm}$. The size of the substrate is $60 \times 40 \mathrm{~mm}^{2}$. The ground plane is printed on the back of the FR4 substrate. The schematic of the proposed antenna design using HFSS software is shown in fig. 2.

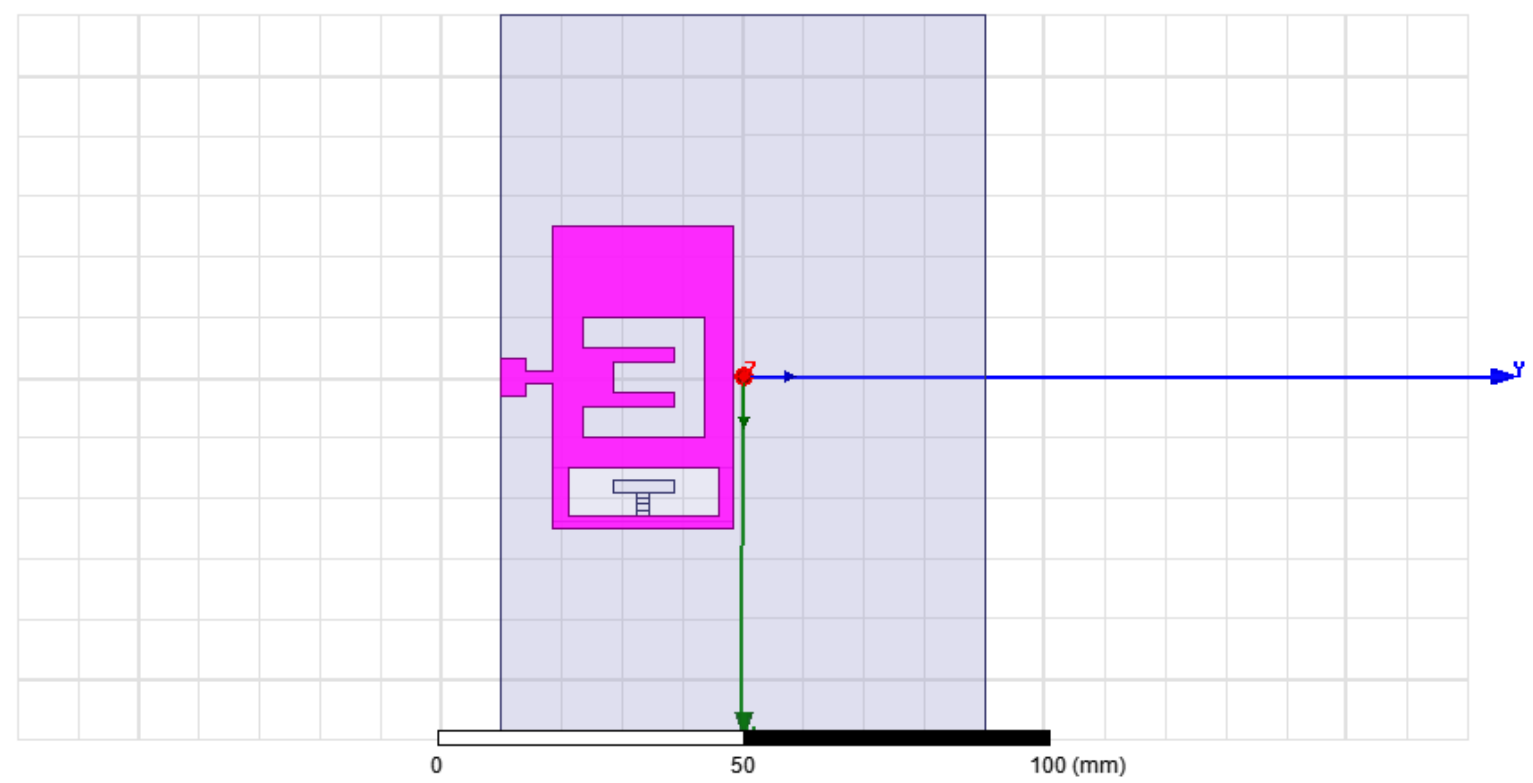

The antenna consists of a rec Figure-2: Schematic of the proposed antenna iich one E-shaped slot and one rectangular patch is emb $25 \times 8 \mathrm{~mm}^{2}$.It consists of 
a parasitic patch of dimensions $10 \times 2 \mathrm{~mm}^{2}$. This parasitic patch is connected to the main driven patch with the help of PIN diode. By activating and deactivating the PIN diode, parasitic patch is connected to the main driven patch. An additional horizontal slot is cut on the ground plane, whose length and width are $30 \mathrm{~mm}$ and $9 \mathrm{~mm}$ respectively as shown in fig. 3 .

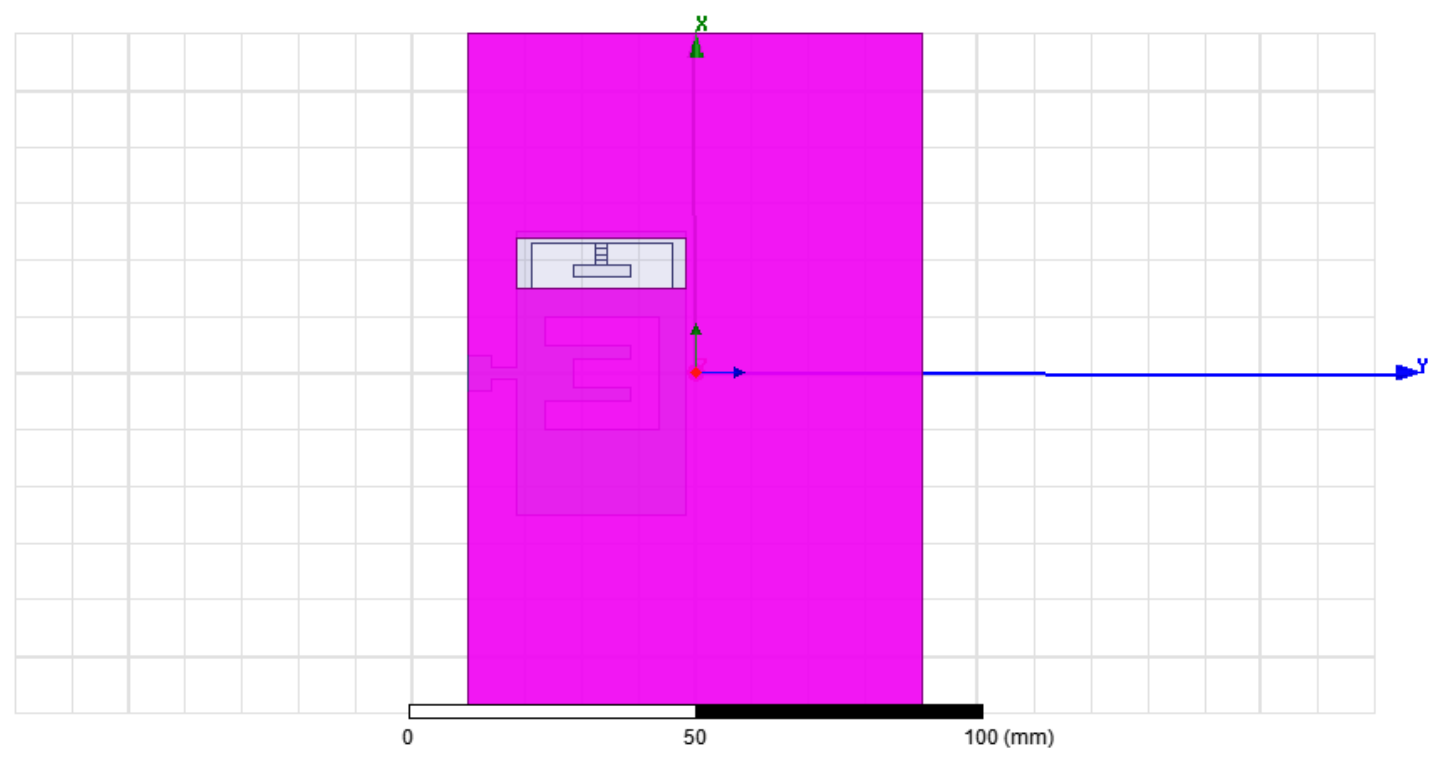

Figure-3: ground plane showing slot

The antenna is fed by a microstrip line of dimensions $6 \times 4 \mathrm{~mm}$. The dimensions of the feed transformer are $4.5 \times 2 \mathrm{~mm}$. The tuning of the antenna parameters is achieved by changing the state of the diode. The dimensions of the ground plane are $60 \times 40 \mathrm{~mm}$. The lengths of the horizontal arms of the E-shape slot are $15 \mathrm{~mm}, 10 \mathrm{~mm}$ and $15 \mathrm{~mm}$ respectively whereas the widths of all the three horizontal arms is $5 \mathrm{~mm}$. The length and width of the vertical arm are $20 \mathrm{~mm}$ and $5 \mathrm{~mm}$ respectively.

\section{SIMULATED RESULTS AND ANALYSIS}

The reconfigurable antenna is simulated using HFSS software in two conditions according to the state of the switch. The tuning of the antenna parameters is achieved by changing the switch conditions. Results of $S_{11}$ for the two conditions are illustrated in fig. 4.

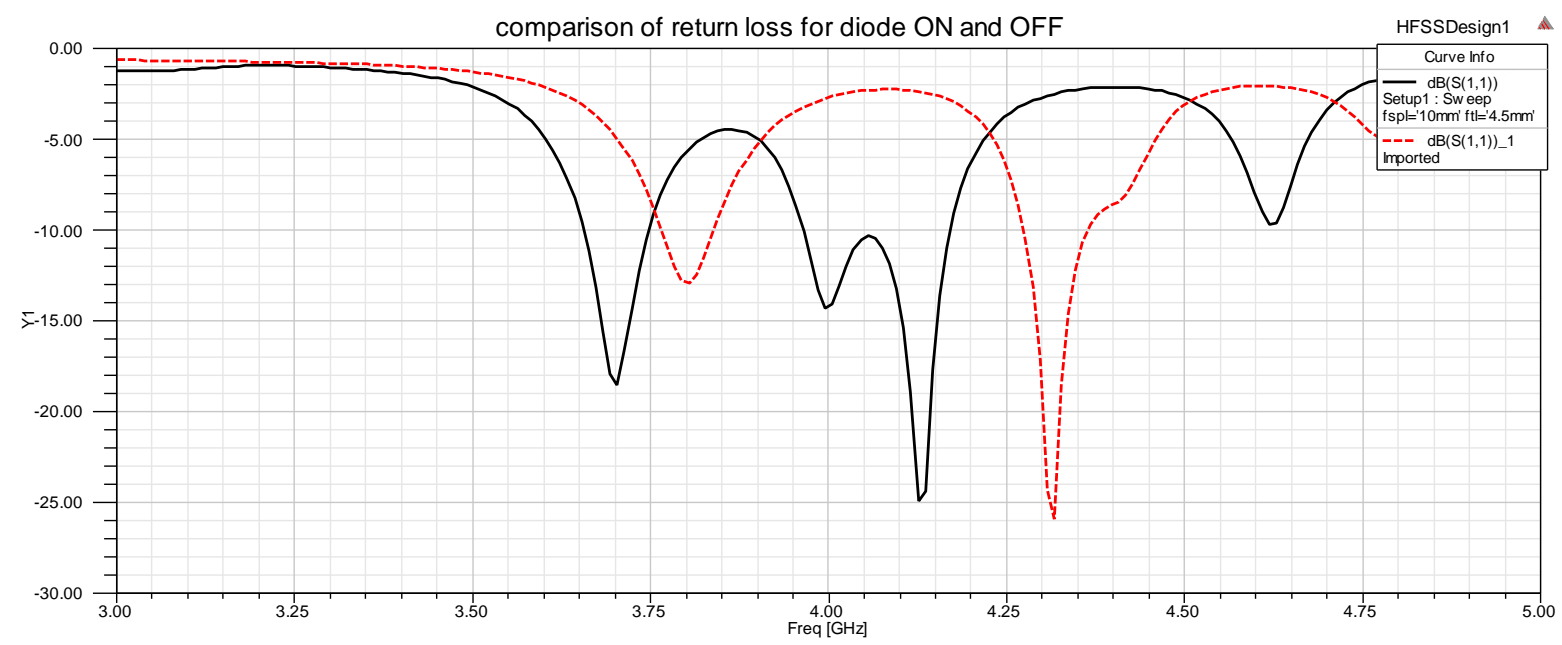

Figure-4: comparison of return loss when the diode is ON and OFF 


\section{International Journal of Recent Trends in Electrical \& Electronics Engg., Apr., 2018. CIJRTE \\ ISSN: 22316612}

When the diode is OFF the first band resonant frequency locates at about $3.8 \mathrm{GHz}$ with the $-10 \mathrm{~dB}$ impedance bandwidth from about $3.76 \mathrm{GHz}$ to $3.83 \mathrm{GHz}$. The second band resonant frequency locates at about $4.3 \mathrm{GHz}$ with the impedance bandwidth from about $4.26 \mathrm{GHz}$ to $4.36 \mathrm{GHz}$. For the desired low band and high band the return loss is $-12.9 \mathrm{~dB}$ and $-25.7 \mathrm{~dB}$ respectively. When the diode is ON the first band resonant frequency locates at about $3.7 \mathrm{GHz}$ with the $-10 \mathrm{~dB}$ impedance bandwidth from about $3.65 \mathrm{GHz}$ to $3.74 \mathrm{GHz}$. The second band resonant frequency locates at about $4.12 \mathrm{GHz}$ with the impedance bandwidth from about $3.96 \mathrm{GHz}$ to $4.17 \mathrm{GHz}$. When the diode is in the on state the return loss for the desired low band and high band is $-18.53 \mathrm{~dB}$ and $-24.93 \mathrm{~dB}$ respectively. The below mentioned table represents the operating frequency, bandwidth and return loss of the proposed/designed antenna in two different switch position.

Table 1: Operating Frequency, BW \& return loss of proposed antenna in two different switch position

\begin{tabular}{|l|l|l|l|l|}
\hline Switch Position & \multicolumn{2}{|c|}{ Bandwidth } & \multicolumn{2}{c|}{ Resonant frequency(GHz) } \\
\cline { 2 - 5 } & Lower band & Upper band & Lower band & Upper band \\
\hline Diode OFF & 3.76 to $3.83 \mathrm{GHz}(70$ & $\begin{array}{l}4.26 \text { to } 4.36 \mathrm{GHz} \\
(100 \mathrm{MHz})\end{array}$ & $3.8 \mathrm{GHz}$ & $4.3 \mathrm{GHz}$ \\
& $\mathrm{MHz})$ & $\begin{array}{l}3.96 \text { to } 4.17 \mathrm{GHz} \\
(210 \mathrm{MHz})\end{array}$ & $3.7 \mathrm{GHz}$ & $4.12 \mathrm{GHz}$ \\
\hline Diode ON & $\begin{array}{l}3.65 \text { to } 3.74 \mathrm{GHz} \\
(90 \mathrm{MHz})\end{array}$ & & \\
& &
\end{tabular}

\section{CONCLUSION AND FUTURE SCOPE}

A compact dual band reconfigurable antenna is presented in which the reconfigurability is achieved by changing the state of the diode. Impedance matching and bandwidth is also increased when the antenna is loaded with the PIN diode. The obtained results show that when the diode is ON the proposed antenna can give two wide frequency bands, in which the low band and high band are $3.65 \mathrm{GHz}$ to $3.74 \mathrm{GHz}$ and $3.96 \mathrm{GHz}$ to $4.17 \mathrm{GHz}$, respectively. It is observed that increasing no. of switches causes reduction in the bandwidth of the sensing antenna.

\section{REFERENCES}

[1]. Haydar M. Al-Tamimi, Salah Mahdi, A Study of Reconfigurable Multiband Antenna for Wireless Application, International Journal of New Technology and Research. (IJNTR) ISSN: 2454-4116, Volume-2, Issue-5, May 2016 Pages 125-134.

[2]. Abirami M, Rajasekar G, Puvaneshwar S ,A Survey of Different Reconfigurable Antennas for Various Wireless Applications, International Journal of Innovative Research in Computer and Communication Engineering Vol. 4, Issue 2, February 2016.

[3]. Ashutosh S. Joshi, M. S. Narlawar, Compact Size Rectangular Patch Reconfigurable Antenna for Cognitive Radio Applications, International Journal of Electrical, Electronics and Data Communication, pp 42-45- Volume-3, Issue-3, March-2015.

[4]. Yahya S. H. Khraisat, Nedal Al-Tawalbeh, Imad A. Abdel-Hafez, Ebrahim Shibly, A Hybrid Reconfigurable Antenna Design for Cognitive Radio System, Journal of Electromagnetic Analysis and Applications, 2013, 5, 328-332.

[5]. Binod Kumar Kanaujia and Babau R. Vishvakarma, Analysis of Gunn Integrated Annular Ring Microstrip Antenna IEEE Transactions on antennas and propagation, Vol. 52, No. 1, January 2004.

[6]. A.K. Singh, Binod K. Kanaujia and B. R. Vishvakarma, "Noise Consideration of Gunn Diode Integrated Annular Ring Microstrip Antenna," International Journal of Microwave and Optical Technology, Vol.5, No.5, September 2010.

[7]. Saneh Surya Phadte, Reconfigurable Antenna Methodologies and Switch Technologies: A Review, International Journal of Innovative Research \& Development Page ,Vol 5 Issue 2 ,pp 308-313.

[8]. N. Haider, D. Caratelli, and A. G. Yarovoy, Recent Developments in Reconfigurable and Multiband Antenna Technology, International Journal of Antennas and Propagation,Volume 2013, Article ID 869170.

[9]. Pagire T. G, Design and Implementation of Re-configurable Antenna, International Journal of Advance Research, Ideas and Innovations in Technology, pp 964-965.

[10]. Sudhina H. K, Ravi M. Yadahalli, N. M. Shetti, Bandwidth Control Using Reconfigurable Antenna Elements, International Journal of Electrical, Computer, Energetic, Electronic and Communication Engineering ,pp 1732-1736,Vol:7, No:12, 2013 
[11]. Dimitrios Peroulis, , Kamal Sarabandi, Linda P. B. Katehi, Design of Reconfigurable Slot Antennas,IEEE Transactions on antennas and propagation, Vol. 53, no. 2, February 2005 ,pp 645

[12]. Randy L. Haupt and Michael Lanagan ,Reconfigurable Antennas, IEEE Antennas and Propagation Magazine, Vol. 55, No. 1, February 2013,49-61

[13]. Ram Singh Kushwaha, D.K.Srivastava, J.P.Saini, A Multi-Slotted Wide Microstrip Patch Antenna for Dual Frequency, International Journal of Computer Science and Information Technologies, Vol. 3 (2), 2012,3523-3525

[14]. T. Sabapathy, M. Jusoh, P.J. Soh, R.B. Ahmad, Radiation Pattern Reconfigurable Antenna: The design challenges at $\mathrm{GHz}$ frequencies, 2016 IEEE Asia-Pacific Conference on Applied Electromagnetics (APACE), 11-13, December 2016 at Langkawi, Kedah, Malaysia

[15]. Mohamed Nasrun OSMAN, Mohamad Kamal A. RAHIM, Peter GARDNER, Mohamad Rijal HAMID, Mohd Fairus MOHD YUS, OFF, Huda A. MAJID, “An Electronically Reconfigurable Patch Antenna Design for Polarization Diversity with Fixed Resonant Frequency”, Radioengineering, Vol. 24, No. 1, April 2015.

[16]. A.K.Singh, Ravi Kumar Gangwar, Binod K. Kannaujia, "Circularly Polarized Annular Ring Microstrip Antenna for High Gain Application," Electromagnetics, Taylor and Francis, Volume 36, no. 6, pp.379391, 2016. 